\title{
EFFECT OF DIFFERENT FABRICATION MATERIALS AND TECHNIQUES ON THE RETENTION OF IMPLANT MESO-STRUCTURES TO TI-BASE ABUTMENTS
}

\author{
Shereen M. Elsayed ${ }^{*}$ and Khalid A. Elbanna**
}

\begin{abstract}
Objectives: The aim of this in-vitro study was to evaluate the effect of the material and the manufacturing technique on the retention of the meso-structure to the Ti-base after artificial thermocycling aging.

Materials and Methods: Forty implant analogs compatible with the Noble Biocare Replace CC regular platform implant system (Dess, Spain) were used in this study to simulate the replacement of an upper second premolar. Implant analogues were placed in epoxy resin moulds. Ti-bases were screwed to the implant analogues. Ti-bases of different groups were scanned using CAD/ CAM scanner and the design of implant abutments was performed using CAD/CAM software. The abutment had two holes with $1 \mathrm{~mm}$ diameter in the mesial and distal surfaces to engage a stainlesssteel wire to facilitate the pull-out testing. The samples were divided into 5 equal groups $(\mathrm{n}=8)$ according to the material and technique of construction of the meso-structure as follows: Group I (Zr CAD): CAD/CAM milled zirconia abutments, Group II (E.max Press): Pressable lithium disilicate abutments with 3D printed resin pattern, Group III (E.max CAD): CAD/CAM milled lithium disilicate abutments, Group IV (PEEK CAD):CAD/CAM milled PEEK abutments, Group V (PEEK Press): 3D-printed resin pattern were fabricated and PEEK (BioHPP, Bredent, Germany) was directly pressed on the Ti-base using a thermal moulding machine (For 2 Press, Bredent, Germany) to fabricate the abutments. The samples of each group were surface treated and cemented to the respective Ti-bases according to the manufacturer's instructions of each material. All the samples were subjected to a total of 10,000 thermal cycles between $5^{\circ} \mathrm{C}$ and $55^{\circ} \mathrm{C}$ to simulate thermal fluctuations intraorally. All samples were subjected to pull-out retention test after thermal aging to separate the abutments from the Ti-base. After pull-out testing, the surfaces of the Tibases and the internal surfaces of the abutments were photographed under high magnification using digital camera to analyze the mode of failure.
\end{abstract}

\footnotetext{
*Associate Professor, Fixed Prosthodontics Department, Faculty of Dentistry, Cairo University, Egypt. Associate Professor, Fixed Prosthodontics Division, Oral and Maxillofacial Department, Faculty of Dentistry, Umm Al-Qura University. **Assistant Professor, Fixed Prosthodontics Division, Oral and Maxillofacial Department, Faculty of Dentistry, Umm Al-Qura University.
} 
Results: Group II (E.max Press) showed the highest significant retentive pull-out load values compared to all other groups and followed by group III (E.max CAD). Group V (PEEK press) showed the lowest significant retentive pull-out load values. Insignificant difference was found between group IV (PEEK CAD) and group I (Zr CAD).

Conclusions: Within the limitations of this study, the following conclusions can be drawn: Lithium disilicate ceramics showed the best results including both CAD/CAM and pressable techniques. CAD/CAM zirconia ceramics and CAD/CAM PEEK abutments have comparable retention values to Ti-Bases. Pressing PEEK on Ti-Base without macro-retentive features is not a reliable alternative to other ceramics used in this study. More clinical trials are still needed to confirm the success of different abutment materials and techniques used to construct mesostructures on Ti-base.

KEYWORDS: Implant abutments, Ti-Base, CAD/CAM, Lithium disilicate, Zirconia, PEEK, PEEK CAD, PEEK Press, Pressable ceramics, Retention, Pull-out testing, E.max Press, Zr CAD

\section{INTRODUCTION}

Implant supported crowns are increasingly gaining popularity among patients and clinicians due to the preservation of the natural dental tissues of the adjacent teeth and the excellent survival rate which is supported by a lot of scientific evidence in the literature including long-term clinical trials. ${ }^{1,2}$ Biologic and mechanical properties of the prosthetic superstructure are vital elements for this long-term success. ${ }^{3-5}$

Implant abutments can be ready-made, or custom made. However, in a lot of cases, the need for individualization of the emergence profile for enhanced biological and esthetic outcome, ease of retrieval, limited inter-occlusal distance and difficulty in removing excess cement require the use of custommade abutments. ${ }^{6}$

Conventionally, custom-made abutments have been casted from a noble metal alloy using a universal casting long abutment (UCLA). Although commonly used, it is of a concern that there is a compromised fit after casting and porcelain firing due to creation of oxidized layer on the fitting surface in addition to the high price of the noble alloy. ${ }^{6,7}$

The use of CAD/CAM implant abutments has increased now in implant dentistry. The entire abutment, including the implant-abutment connection can be milled or only the coronal part is milled where the connection is provided by the manufacturer. ${ }^{8}$ More often than not, the metallic color of both types, even when placed subgingivally, may shine through or give an unnatural bluish discoloration to the gingival mucosa. This problem is aggravated in the anterior area with thin gingival biotype ${ }^{9}$.

As zirconia printed its footstep in the dental ground, several manufacturers and $\mathrm{CAD} / \mathrm{CAM}$ systems introduced custom-made zirconia abutments due to their physical, mechanical and optical properties ${ }^{10,11}$ Nevertheless, a higher rate of failure than titanium abutments was reported at the implant-abutment connection or the transmucosal part of the abutment ${ }^{12}$. Besides fracture at the apical part, fretting wear lead to uncertainty of its longterm success ${ }^{13-16}$.

Consequently, titanium base (Ti-base) has been introduced to combine the advantages of a titaniumtitanium connection and the esthetics of a toothcolored abutment. Two designs are possible with this solution; hybrid abutment-crown as one piece bonded directly to the Ti-base which is later screwed to the implant, or hybrid abutment that acts as a meso-structure bonded to the Ti-base and screwed to the implant then a separate all-ceramic crown is later cemented on top of it ${ }^{17}$. 
This allows the standard component supplied by the manufacturer to serve as a custom-made solution either screw-retained or cement-retained. This customization improves the tissue adaptation and emergence profile ${ }^{18}$. The deep placement of the metallic part below the soft tissue margin enhances the esthetic outcome ${ }^{19,20}$. On top of that, it allows the milling of a corrected-angle core for improperly placed implants ${ }^{21}$.

The extra-oral cementation of the superstructure to the Ti-base eliminates the problem of deep and inaccessible excess cement around the implant head as the restoration becomes screw-retained in the case of one-piece hybrid abutment-crown whereas in the case of a hybrid abutment with a separate crown, the margin of the restoration is placed equigingivally or slightly subgingivally where excess cement can be easily removed..$^{22,23}$

One main advantage of the Ti-base is the versatility of the construction technique of the restoration; it can be constructed in a fully analog technique with conventional impression and laboratory procedures, yet it can be constructed entirely with a digital workflow from digital impressions of the scan body to $\mathrm{CAD} / \mathrm{CAM}$ fabrication of abutment and crown. Most common CAD/CAM systems have increasing data-base library for fabrication of restorations on Ti-base. ${ }^{8}$ A "split-file" technique is used to virtually design two components that fit each other intimately, eliminating the need of intermediate steps that add time and resources. Restorations could be designed from implant up and split this restoration into separate components: a custom-made abutment and a crown. ${ }^{17}$

CAD/ CAM technology is not only restricted to subtractive manufacturing where the crown or abutment can be milled or grinded from a block or a disc, but also additive manufacturing can be used to fabricate a wax pattern, which in turn, can be used either by heat-pressing or compression moulding techniques to fabricate the superstructure. ${ }^{24}$
Due to the huge advancement in technologies and materials, the use of Ti-base nowadays ranges from single tooth replacement to full-arch prostheses with a plethora of dental materials available for each purpose. ${ }^{25}$

When used as abutments on Ti-base, zirconia has shown good results and high fracture resistance ${ }^{26}$. They have much higher fracture strengths than pure zirconia abutments and two-piece zirconia abutments for single tooth restorations in the anterior region. ${ }^{26-29}$

Good mechanical properties and high translucency led to the introduction of lithium disilicate ceramic with Ti-base as abutment or as abutment crown. ${ }^{30-32}$ Lithium disilicate can be used with Ti-base either by the heat-pressed or CAD/ CAM techniques. Lithium disilicate blanks with prefabricated connection geometry for Ti-base are now available for most of the implant systems. ${ }^{33,34}$ It is suggested that lithium disilicate can be bonded to Ti-base easier than zirconia. ${ }^{33-35}$

The use of ceramic-reinforced polyetheretherketone (PEEK) is rather new in dentistry but has been more frequently used in the last years due to its color, similar elastic modulus to dentin, high biocompatibility, low plaque retention, hypoallergenicity and good abrasion resistance and polishability. They can be used as abutments by two methods of fabrication; CAD/CAM using PEEK discs or compression moulding using lost wax technique. A study found that PEEK is appropriate for use as abutment with Ti-base for anterior area. ${ }^{26}$

The adhesive connection between the Ti-base and the ceramic coping was found to be the weakest link of this type of abutment. ${ }^{36}$ It is of utmost importance to achieve high and durable bonding strength at the Ti-base-abutment interface, albeit, there is no consensus on the bonding protocol to Tibase. The bond at this interface is influenced by a lot of factors; the Ti-base height, texture, mesostructure surface treatment and fit, which is in part dependent on the manufacturing technique, in addition to the cement type. ${ }^{37-39}$ 
The aim of this study was to evaluate the effect of the material and the manufacturing technique on the retention of the meso-structure to the Ti-base after artificial thermo-cycling aging. The first null hypothesis assumes that the technique of construction of the implant abutment has no effect on the retention of the abutments to the Ti-base. The second null hypothesis stated that the material of construction of the implant abutment has no effect on the retention of the abutments to the Ti-base.

\section{MATERIALS AND METHODS}

Forty implant analogs compatible with the Noble Biocare Replace CC regular platform implant system (Dess, Spain) were used in this study to simulate the replacement of an upper second premolar. Epoxy resin (Chemapoxy 150, CMB, Giza, Egypt) was poured into square moulds and the implant analogs were placed in a vertical direction using a dental surveyor (Ney, DeguDent GmbH, Germany) until $2 \mathrm{~mm}$ of the coronal part were left exposed..$^{40,41}$ They were left until complete setting of the epoxy resin. Forty Ti-bases with $1.2 \mathrm{~mm}$ gingival height and 5 mm abutment height (Dess, Barcelona, Spain) were screwed into their respective implant analogs using a torque wrench at $15 \mathrm{Ncm}$. (Fig 1). The Ti-base has internal conical connection to match the implant geometry.

A scan body (Dess, Barcelona, Spain) was placed on the Ti-base and scanned using a laboratory scanner (Swing, DOF, Seoul, Korea) and the scan was exported to the software (Exocad, Darmstadt, Germany) to design the abutment. The abutments were designed with a standardized dimension according to the dimensions of prepared upper second premolar as follows: $12 \mathrm{~mm}$ occlusogingival height, $6.5 \mathrm{~mm}$ bucco-lingual width, 5.5 $\mathrm{mm}$ mesio-distal width, $0.5 \mathrm{~mm}$ chamfer finish line and $2.5 \mathrm{~mm}$ screw channel. ${ }^{24}$ (Fig.2). The abutment had two holes with $1 \mathrm{~mm}$ diameter in the mesial and distal surfaces to engage a stainless-steel wire to facilitate the pull-out testing. ${ }^{40}$ The cement space was adjusted to be $50 \mu \mathrm{m}$ starting $0.5 \mathrm{~mm}$ from the margin. The design was later exported to different manufacturing machines to fabricate the abutments according to each group.

The samples were divided into 5 equal groups $(n=8)$ according to the material and technique of construction of the mesostructure (abutment) as follows:

Group I (Zr CAD): CAD/CAM milled zirconia abutments were milled from zirconia discs (Zolid HT, Ammann Girrbach, Austria) by a 5-axis milling machine (Ceramill Motion 2, Ammann Girrbach, Austria). The milled abutments were then sintered in a zirconia furnace (Ceramill Therm, Ammann Girrbach, Austria) with $8^{\circ} \mathrm{C} / \mathrm{min}$ rise till $1450{ }^{\circ} \mathrm{C}$ where it was kept for 2 hours and then decreased with $20^{\circ} \mathrm{C} / \mathrm{min}$.

Group II (E.max Press): The standard tessellation language (STL) files of the abutments were sent from the CAD software to the $3 \mathrm{D}$ printing machine (EPAX, North Carolina, USA) and a 3D-printed resin pattern were fabricated layer-by-layer with $12 \mu \mathrm{m}$ layer thickness until each abutment was fully built. The patterns were sprued, invested and heatpressed with lithium disilicate ingots (E.max Press, Ivoclar Vivadent, Schaan, Lichtenstein) in a heat press furnace (Programat EP 5010, Ivoclar Vivadent, Schaan, Lichtenstein) according to manufacturer's instructions. Devesting of the abutments were done using airborne particle abrasion $\left(50 \mu \mathrm{m} \mathrm{Al}_{2} \mathrm{O}_{3}\right.$ at 1 bar and 30 PSI) followed by finishing of the abutments using diamond discs and finishing kit according to manufacturer's instructions.

Group III (E.max CAD): CAD/CAM milled lithium disilicate abutment were milled from lithium disilicate blocks (E.max CAD, Ivoclar Vivadent, Schaan, Lichtenstein) using a milling machine (Ceramill Motion 2, Ammann, Girrbach, Austria) which were eventually crystalized in a firing furnace (Programat P510, Ivoclar Vivadent, 
Lichtenstein) for 30 minutes at $850^{\circ} \mathrm{C}$ according to manufacturer's instructions.

Group IV (PEEK CAD): CAD/CAM milled PEEK abutments were milled from PEEK blanks (BreCAM BioHPP, Bredent GmbH, Germany) using a milling machine (Ceramill Motion 2, Ammann Girrbach, Austria). Silicon polisher (Ceragum Wheel, Bredent, Germany) and polishing paste (Abraso-starglanz, Bredent, Germany) were used for finishing of the abutment according to manufacturer's instructions.

Group V (PEEK Press): 3D-printed resin patterns were fabricated as previously mentioned in Group II using the same 3D printer machine. The wax patterns were invested in a mould with a special investment material (Brevest for 2 Press investment material,
Bredent, Germany). The wax patterns were melted after being placed in a pre-heating oven and the mould is heated until $630^{\circ} \mathrm{C}-850^{\circ} \mathrm{C}$. The mould was allowed to cool down until reaching $400^{\circ} \mathrm{C}$. PEEK (BioHPP, Bredent, Germany) was directly pressed on the Ti-base using a thermal moulding machine (For 2 Press, Bredent, Germany) to fabricate the abutment. The mould is placed at room temperature for 35 minutes to cool down while maintaining the pressure then devesting was done.

Materials, manufacturers names and chemical composition of materials used in this study are presented in Table (1). Flow chart of the sample grouping and study methodology is shown in Fig. (3). Different abutments materials and techniques after being constructed are shown in Fig. (4).

TABLE (1): Materials, manufacturers names and chemical co mposition of materials used in this study.

\begin{tabular}{|c|c|c|}
\hline Material & Manufacturer Name & Chemical Composition \\
\hline Zr CAD (Zolid HT) & Ammann Girrbach & $\begin{array}{l}\mathrm{ZrO} 2+\mathrm{HfO} 2+\mathrm{Y} 2 \mathrm{O} 3: \geq 99.0 \%, \mathrm{Y} 2 \mathrm{O} 3: 6,7-7,2 \% \\
\mathrm{HfO} 2: \leq 5 \%, \mathrm{~A} 12 \mathrm{O} 3: \leq 0.5 \%, \text { Other oxides: } \leq 1 \%\end{array}$ \\
\hline $\begin{array}{l}\text { Lithium disilicate glass } \\
\text { ceramic (E.max Press) }\end{array}$ & Ivoclar Vivadent & $\begin{array}{l}\mathrm{SiO} 2 \text {, } \mathrm{Li} 2 \mathrm{O}, \mathrm{K} 2 \mathrm{O}, \mathrm{P} 2 \mathrm{O} 5, \mathrm{ZrO} 2, \mathrm{ZnO} \text {, other oxides } \\
\text { and ceramic pigments }\end{array}$ \\
\hline $\begin{array}{l}\text { Lithium disilicate glass } \\
\text { ceramic (E.max CAD) }\end{array}$ & Ivoclar Vivadent & $\begin{array}{l}57-80 \% \mathrm{SiO} 2,11-19 \% \mathrm{Li} 2 \mathrm{O}, \mathrm{K} 2 \mathrm{O}, \mathrm{MgO}, \mathrm{A} 12 \mathrm{O} 3 \text {, } \\
\mathrm{P} 2 \mathrm{O} 5 \text { and other oxides }\end{array}$ \\
\hline $\begin{array}{l}\text { BreCAM BioHPP } \\
\text { (PEEK CAD) }\end{array}$ & Bredent GmbH \& Co KG & PEEK, $20 \%$ weight titanium oxide \\
\hline $\begin{array}{l}\text { BreCAM BioHPP } \\
\text { (PEEK Press) }\end{array}$ & Bredent GmbH & PEEK, $20 \%$ weight titanium oxide \\
\hline IPS ceramic etching gel & Ivoclar Vivadent & $4 \%$ Hydroflouric acid \\
\hline Monobond plus & Ivoclar Vivadent & $\begin{array}{l}\text { Ethanol, 3-(trimethoxysilyl)propyl methacrylate, } \\
\text { methacrylated phosphoric acid ester }\end{array}$ \\
\hline Visio Link & Bredent GmbH \& Co KG & MMA, pentaerythritol triacrylate, photoinitiators \\
\hline $\begin{array}{l}\text { DTK Kleber adhesive resin } \\
\text { cement }\end{array}$ & Bredent $\mathrm{GmbH}$ & $\begin{array}{l}\text { Dual-curing two component material based on } \\
\text { methacrylates, inorganic fillers, and initiators. }\end{array}$ \\
\hline
\end{tabular}




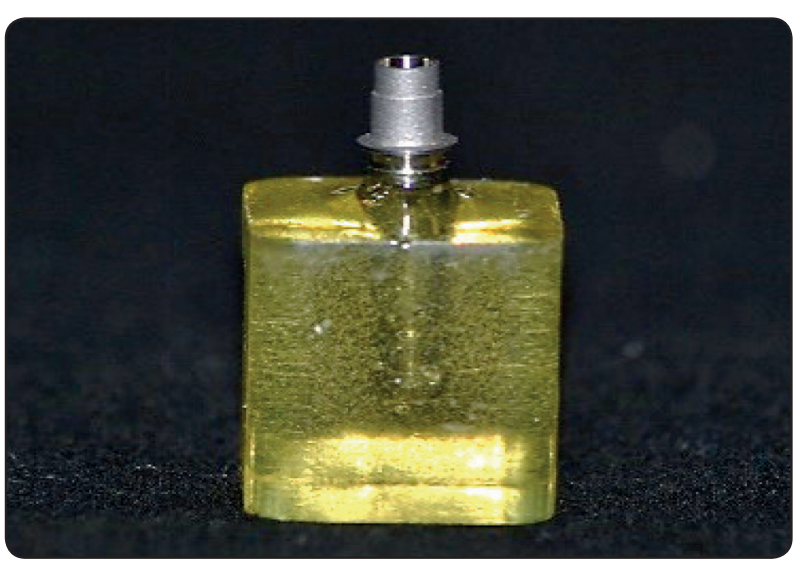

Fig. (1): Ti-Base screwed into implant analogue.

The samples of each group were surface treated and cemented to the respective Ti-base according to the manufacturer's instructions (Table 2) as follows:

Group I: The fitting surface of the abutments were sandblasted using alumina particles $50 \mu \mathrm{m}$. A

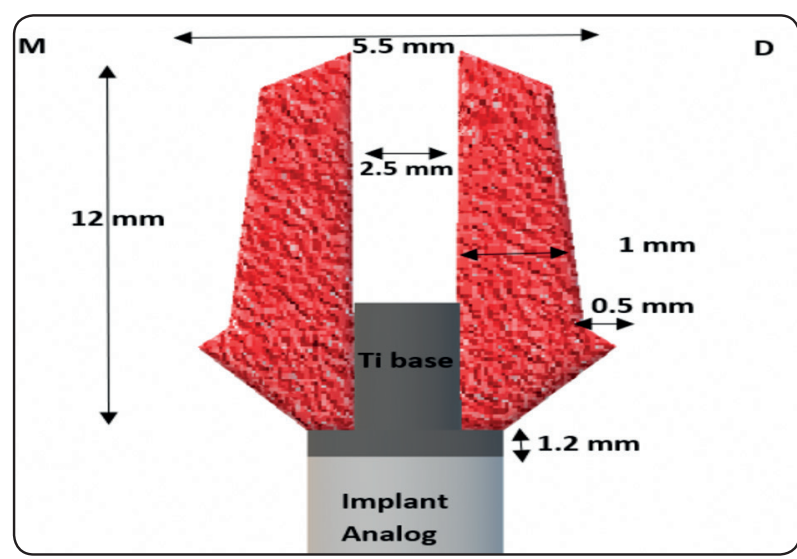

Fig. (2): Diagram showing the standardized dimensions of the abutments.

zirconia primer (MKZ-Primer, Bredent, Germany) was applied to the abutments for 30 seconds.

Group II and III: Hydrofluoric acid 5\% (IPS Ceramic Etching Gel, Ivoclar Vivadent, Lichtenstein) was placed on the fitting surface of the abutments for 20 seconds then rinsed and dried. A

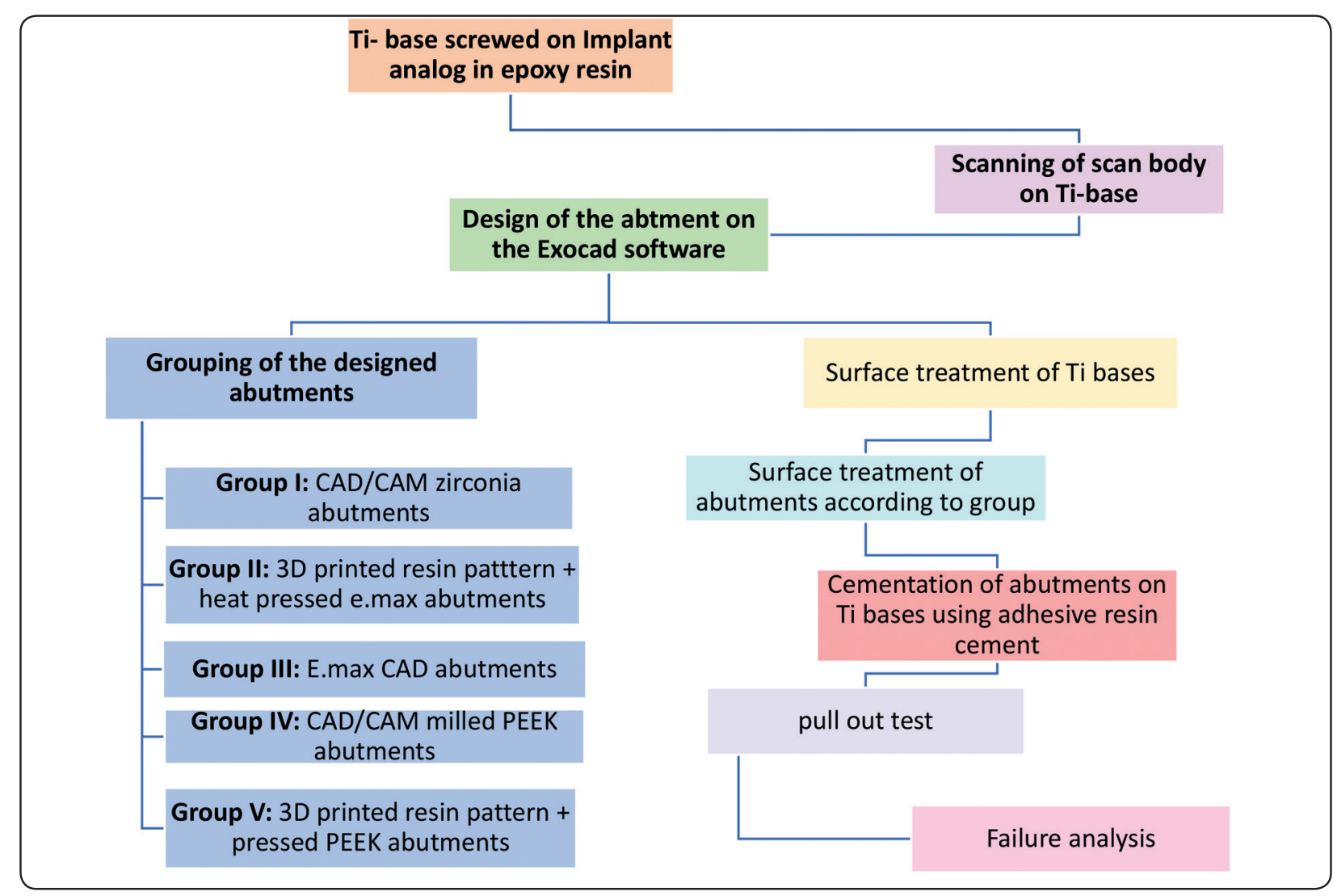

Fig. (3): Flow chart showing the sample grouping and study methodology. 
TABLE (2): Surface treatments of different materials assigned for different groups.

\begin{tabular}{|l|l|l|}
\hline Group & Type of material & Surface treatment \\
\hline Group I & $\begin{array}{l}\text { CAD/CAM Zirconia } \\
\text { abutments }\end{array}$ & $\begin{array}{l}\text { sandblasted using alumina particles } 50 \mu \mathrm{m} \text {. A zirconia primer (MKZ- } \\
\text { Primer, Bredent, Germany) was applied to the abutments for 30 seconds. }\end{array}$ \\
\hline Group II & $\begin{array}{l}\text { Heat-pressed Lithium } \\
\text { disilicate abutments }\end{array}$ & $\begin{array}{l}\text { Hydrofluoric acid 5\% (IPS Ceramic Etching Gel, Ivoclar Vivadent, } \\
\text { Lichtenstein) was placed on the fitting surface of the abutments for 20 } \\
\text { seconds then rinsed and dried. A thin layer of silane coupling agent } \\
\text { (Monobond Plus, Ivocalar Vivadent, Lichtenstein) was then applied and air } \\
\text { thinned. }\end{array}$ \\
\hline Group III & $\begin{array}{l}\text { CAD/CAM lithium } \\
\text { disilicate abutments }\end{array}$ & $\begin{array}{l}\text { Hydrofluoric acid 5\% (IPS Ceramic Etching Gel, Ivoclar Vivadent, } \\
\text { Lichtenstein) was applied to the fitting surface of the abutments for } \\
\text { 20 seconds then rinsed and dried. A thin layer of silane coupling agent } \\
\text { (Monobond Plus, Ivocalar Vivadent, Lichtenstein) was then applied and air } \\
\text { thinned. }\end{array}$ \\
\hline Group IV & $\begin{array}{l}\text { CAD/CAM PEEK } \\
\text { abutments }\end{array}$ & $\begin{array}{l}\text { The fitting surfaces were sandblasted with 110 } \mu \mathrm{m} \text { aluminum oxide at } \\
\text { a pressure of 2-3 bars. A layer of PEEK primer (Visio Link, Bredent, } \\
\text { Germany) was applied to the fitting surface of the abutments and cured in a } \\
\text { light polymerization device for 90 seconds. }\end{array}$ \\
\hline Group V & Press abutments & \begin{tabular}{l} 
No surface treatment. \\
\hline
\end{tabular}
\end{tabular}

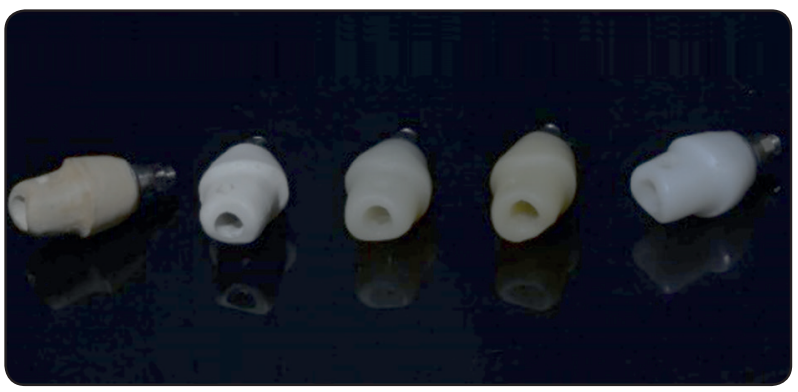

Fig. (4): Different abutments materials and techniques after being constructed.

thin layer of silane coupling agent (Monobond Plus, Ivocalar Vivadent, Lichtenstein) was then applied and air thinned.

Group IV: The fitting surface of the PEEK abutments was sandblasted with $110 \mu \mathrm{m}$ aluminum oxide at a pressure of 2-3 bars. A layer of PEEK primer (Visio Link, Bredent, Germany) was applied to the fitting surface of the abutments and cured in a light polymerization device for 90 seconds. The conditioned area had a semi-matt finish at that point making the perfect layer thickness.
Group V: No surface treatment was done as the abutments were directly pressed on the Ti-bases.

Metal primer (MKZ-Primer, Bredent, Germany) was applied to the Ti-bases for 30 seconds. Finally, the abutments of all groups were cemented to their respective Ti-bases using MDP phosphate ester dual cure adhesive resin cement (DTK Kleber, Bredent, Germany) and a finger pressure was applied over the abutments for 2 minutes. The cement was polymerized for 180 seconds in a polymerization unit (BreLux Power Unit 2, Bredent, Germany) then the excess cement was removed. Fig. (5).

\section{Thermal aging and storage:}

All the samples were subjected to thermal aging in a moist environment to simulate temperature alterations in the oral cavity. The samples were exposed to a total of 10,000 thermal cycles between $5^{\circ} \mathrm{C}$ and $55^{\circ} \mathrm{C}$ with a $30 \mathrm{sec}$ soaking time and 10 sec pause time between different baths, where the samples were exposed to room temperature. After 


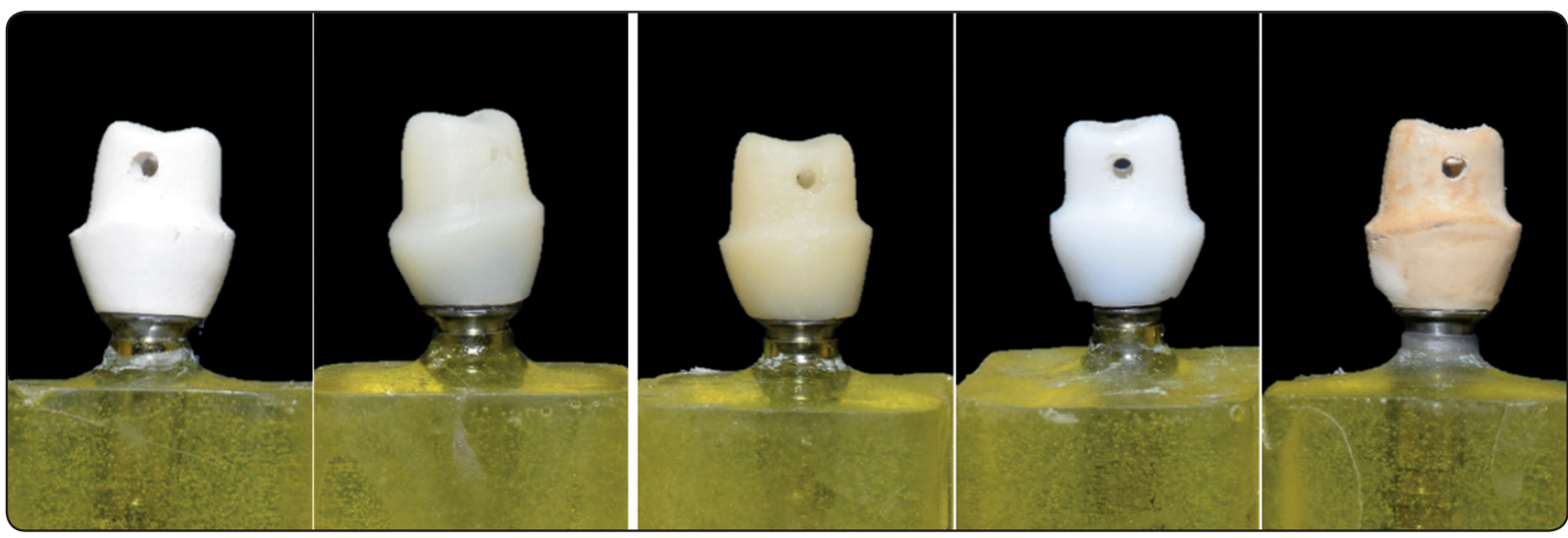

Fig. (5): Different abutments of all groups cemented to their respective Ti-bases.

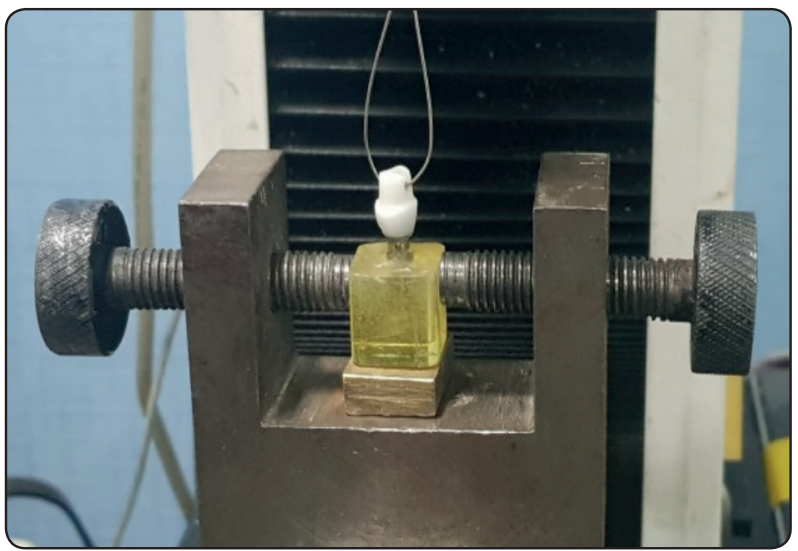

Fig. (6): Pull-out Retention Testing.

thermal aging, the samples were stored in a heating cabinet at $23^{\circ} \mathrm{C}$ for 24 hours..$^{42,43}$

\section{Pull-out Retention Testing:}

All samples were subjected to pull-out retention test after thermal aging to separate the mesostructure (abutments) from the Ti-base. A stainlesssteel wire of $1.8 \mathrm{~mm}$ was introduced into the two holes which was included in the design of the abutment mesially and distally. Pull-out testing was performed using Materials Testing Machine (Model 3345; Instron Industrial Products, Norwood, USA) with a loadcell of $5 \mathrm{kN}$. Data were recorded using computer software (Bluehill Lite; Instron Instruments). The abutment was suspended from the upper movable compartment of the testing machine by the stainless-steel wire and the device was subjected to a slowly increasing vertical load $(1 \mathrm{~mm} / \mathrm{min})$ until total abutment dislodgment from Ti bases. Fig. (6). The load required to dislodgment was recorded in Newton.

\section{Failure Mode Analysis}

After pull-out testing, the surfaces of the Ti-base and the internal surfaces of the abutments were photographed with high magnification using digital camera (Nikon 3100) to analyze the remnants of the cement on either the Ti-base surface or the fitting surface of the abutments quantitatively. Failure modes were categorized as follows: Type 1: remnants of the cement were found mainly on TABLE (3): Mean and SD of retentive pull-out load values(N) of the tested groups.

\begin{tabular}{|l|r|r|r|r|r|r|}
\hline & \multicolumn{1}{|l|}{ E.max CAD } & \multicolumn{2}{l|}{ E.max Press } & \multicolumn{1}{l|}{ PEEK CAD } & \multicolumn{1}{l|}{ PEEK Press } & \multicolumn{2}{l|}{ Zr CAD } & p-value \\
\hline Mean $(\mathrm{N})$ & $344.44^{\mathrm{b}}$ & $355.26^{\mathrm{a}}$ & $223.62^{\mathrm{c}}$ & $203.94^{\mathrm{d}}$ & $226.59^{\mathrm{c}}$ & $<0.001$ \\
\cline { 1 - 3 } & 3.44 & 3.97 & 3.26 & 2.37 & 2.84 & \\
\hline
\end{tabular}

Different letter within mean row indicates significant difference (Tukey's HSD) 


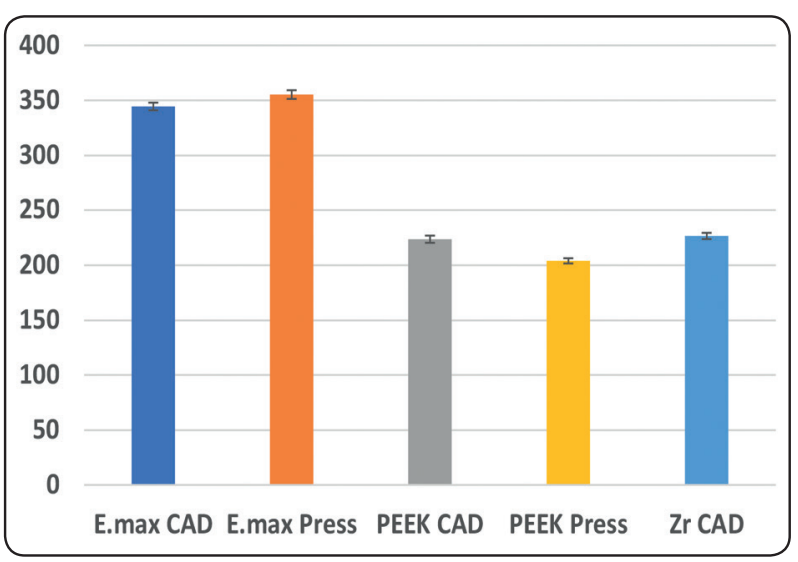

Fig. (7): Bar chart showing mean retentive pull-out load values of different tested groups.

the Ti-base surface; Type 2: remnants of the cement were found on both the Ti-base surface and the fitting surface of the abutments; Type 3: remnants of the cement were found mainly on the fitting surface of the abutments. ${ }^{44}$

\section{Statistical analysis}

Data was explored for normality using Shapiro Wilk test and showed parametric distribution. One Way ANOVA was used to compare between tested groups followed by Tukey's HSD post hoc test for multiple comparisons. Significant level was set at $\mathrm{p}=0.05$. Statistical analysis was performed with IBM® SPSS ${ }^{\circledR}$ Statistics Version 20 for Windows.

\section{RESULTS}

The mean and standard deviation (SD) of the five tested groups were shown in Table (3) and Fig. (7). The results of One-Way ANOVA revealed that the abutment material and manufacturing technique had a statistically significant effect on mean retentive pull-out load values. Group II (E.max Press) showed the highest significant retentive pull-out load values compared to all other groups and followed by group III (E.max CAD). Group V (PEEK Press) showed the lowest significant retentive pull-out load values. Insignificant difference was found between group IV (PEEK CAD) and group I (Zr CAD).

\section{Mode of failure analysis:}

Failure mode was revealed as Type 1 for all samples of group I ( $\mathrm{Zr} \mathrm{CAD)} \mathrm{where} \mathrm{almost} 90 \%$ of the cement remained attached to the Ti-bases. Regarding group II (E.max Press) and group III (E.max CAD), the results showed that $90 \%$ of the samples had Type 3 failure mode and $10 \%$ of the samples revealed Type 2 failure mode. As for group IV (PEEK CAD), Type 2 failure mode was the predominant type of failure for most of the samples where remnants of cement were found on both the Tibase surface and the fitting surface of the abutments. Group V (PEEK Press) samples in which there was no cement used, showed parts of the PEEK material being attached to the Ti base in $50 \%$ of the samples of this group while the other half showed almost no attached parts of the PEEK material to the Ti-base. Figs. (8-11) showed different types of failure mode.

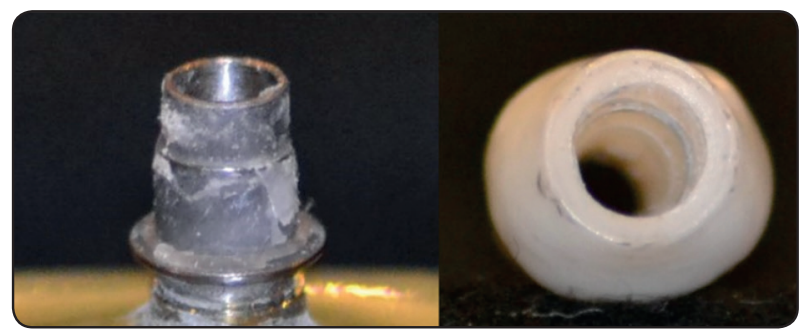

Fig. (8): Representative sample showing Type 1 Failure mode.

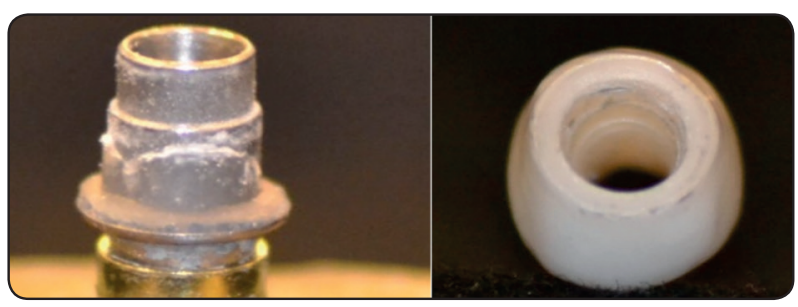

Fig. (9): Representative sample showing Type 2 Failure mode.

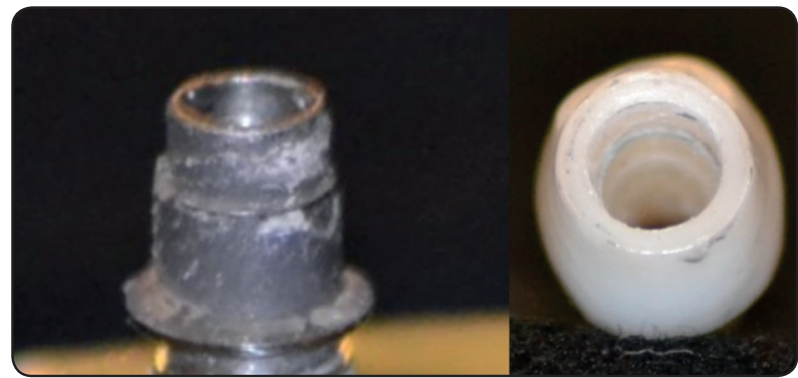

Fig. (10): Representative sample showing Type 3 Failure mode. 


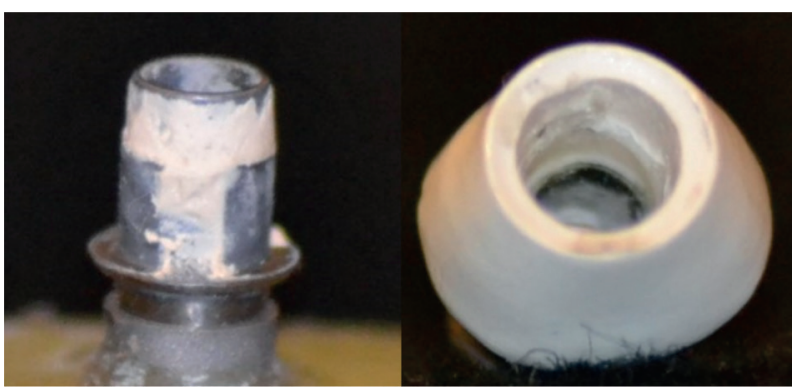

Fig. (11): Failure mode of group V (PEEK Press).

\section{DISCUSSION}

The paradigm shift in recently introduced digital workflow of oral implantology and CAD/ CAM technology has reached an advanced level of development. ${ }^{24}$ The overlap between these two advanced categories in dentistry in addition to the innovative enhancement in all-ceramic materials and polymer-based materials led to the introduction of novel treatment strategies and concepts for replacement of missing single tooth through implant-supported restorations. ${ }^{45}$

The selection of implant abutments which represent the link between osseo-integrated implant fixtures and implant superstructure is crucial in gaining functional and esthetic rehabilitation. 7,8 The use of all-ceramic abutments has gained a wide popularity owing to the esthetic requirements needed by both the prosthodontists and the patients. The technical complications that have been encountered with the use of the most popular all-ceramic CAD/ CAM zirconia abutment represented in the form of greater wear within the connection between the extremely hard zirconia abutments and sensitive titanium fixtures at the implant-abutment interface resulted in its decline. ${ }^{46}$ The launching of the hybrid retention Ti-Base concept has gained wide acceptance nowadays and has been provided as a more successful alternative to all-ceramic zirconia abutments with the benefits of esthetics, customized emergence profile, lack of ceramic material at the implant-abutment junction, retrievability and well controlled bonding procedures extraorally with the absence of the risk of incomplete cement removal. ${ }^{40,41}$

Ti-Base abutments are abutments having their geometries stored in CAD/CAM software systems for quick restoration construction. They merge between the advantages of the cement-retained and screw-retained abutments, the prefabricated and custom-made abutments, the machine-made titanium-to-titanium connection of the Ti-Base to the implant in conjunction with the all-ceramic abutment cemented onto the titanium base has given this innovative implant abutment option an exclusive feature. ${ }^{(40)}$ Accordingly, Ti-Base concept was selected in the present study. However, bonding of the implant abutment onto the Ti-Base has been reported as one of the challenges that might face this new concept. ${ }^{47}$ Cementation protocols for Ti-Base abutments has been rarely discussed in the literature. ${ }^{48}$ Factors that may affect the success of the bond between Ti-Base and the ceramic components include the Ti-Base height, surface texture, superstructure fit and material, cement type and surface treatment of the ceramic component. ${ }^{44,47}$

Different ceramic and polymer-based materials have been tried recently over the Ti-Base abutments. All-ceramic zirconia and lithium disilicate abutments are the most widely used custom-made abutments. ${ }^{46}$ On the other hand, the new ceramicreinforced Polyetheretherketone (PEEK) material might meet the requirements for final implantsupported restorations. ${ }^{49,50}$ However, limited data on this material has been reported in the literature. Hence, our interest has been raised to examine this new material in comparison to the most popular ceramic materials.

The results of this study showed that there was a statistically significant difference in pull-out retention values between all groups except PEEK CAD (group IV) and Zr CAD (group I) groups where there was no statistically significant difference. 
E.max Press group (group II) revealed the highest pull-out retention values followed by E.max CAD group (group III). This may be attributed to the well-known bonding capabilities of the etchable lithium disilicate glass-ceramics to resin cements. This was confirmed by the mode of failure of this type of abutment (Type 3) with most of the cement remained on the fitting surface of the abutment. Fig (10). This was consistent with the study done by Maltzahn et al ${ }^{46}$ who concluded that the weakest link was the bonding between lithium disilicate and the Ti-base and the fracture pattern revealed durable bond between glass-ceramics and resin cement. Similarly, a previous study emphasized the greater bond strength values with lithium disilicates owing to the high silica content within the material and superior chemical bond between lithium-disilicate crystals and silane coupling agent. They highly recommend the use of lithium disilicate ceramics as custom-made hybrid implant abutments regarding their fracture resistance and bond strength. ${ }^{51}$

The first null hypothesis stating that the technique of construction would not affect the retention of abutments on Ti-Base was rejected. Lithium disilicate ceramics have been known by two techniques of construction; either by $\mathrm{CAD} /$ CAM or Pressing technology. Moreover, within the pressing technique itself, the step of the wax pattern construction could be designed with different technologies such as manual conventional technique, subtractive $\mathrm{CAD} / \mathrm{CAM}$ technique as well as the additive $3 \mathrm{D}$ manufacturing technique. ${ }^{24}$ In this study, the two techniques for construction of lithium disilicate E.max ceramic were selected: the $\mathrm{CAD} / \mathrm{CAM}$ technique and the pressing technique using the $3 \mathrm{D}$ printing for wax pattern fabrication. The E.max Press abutments showed higher pullout retention values than E.max CAD abutments and the difference was statistically significant. Better internal adaptation of the E.max Press abutments than E.max CAD abutments might give a logic explanation to this finding. Better internal adaptation may have resulted in better retentive values. However, there was a controversy whether the $\mathrm{CAD} / \mathrm{CAM}$ technique or pressing technique could be able to produce more accurately fitted lithium disilicate ceramic restorations. One study revealed that fabrication of E.max glass-ceramic restorations using manual layering wax pattern technique and subsequent pressing resulted in more accurately fitted restorations than CAD/CAM milled restorations in terms of marginal and internal fit. ${ }^{52}$ Other studies related the accuracy of the internal fit of the CAD/CAM milled restorations to the accuracy of the scanning followed by the milling step of the CAD/CAM system itself emphasizing the differences between the CAD/CAM machines and the significance of benefitting of the newly updated 5-axis milling machines for better accuracy. ${ }^{53-56} \mathrm{On}$ the contrary, some studies reported no significant differences between pressing or CAD/CAM techniques in producing accurately fitted lithium disilicate restorations or even better accurately fitted restorations with CAD/CAM technology. ${ }^{57,58}$

It is of significance to mention that the application of $3 \mathrm{D}$ printing technique during wax pattern construction might have resulted in these results, owing to better internal adaptation and therefore even cement distribution. This was concluded previously in several studies. ${ }^{59,60}$ They proved that better internal adaptation of dental restorations could be reached through additive manufacturing techniques than by using manual lost wax technique or subtractive techniques. It was concluded that obtaining the dental object by building it layer by layer through 3D printing might reproduce better internal adaptation at undercut areas and sharp internal angles with less material waste. ${ }^{61-63}$ Oppositely, the internal adaptation of the dental restorations milled with $\mathrm{CAD} /$ CAM additive milling machines always suffer from poor internal adaptation owing to the mismatch between cutting milling tool of the machine, the small undercuts and sharp internal angles found on the object being milled..$^{61,62}$ 
Conversely, it was found formerly that additive manufacturing technique might affect the final product negatively as material shrinkage during polymerization may accumulate residual stresses resulting in porosities in-between layers which may possibly affect the adhesion between them. Inbetween layers may deform during polymerization and interlayer binding may be affected by heat. Thus, this technology could be reported as being technique-sensitive and could be affected by polymer photo-initiator and irradiation exposure parameters as wavelength, power and exposure time or velocity. ${ }^{64,65}$ This was found in previous studies where they revealed better internal adaptation with $\mathrm{CAD} / \mathrm{CAM}$ milled patterns than additive manufacturing techniques. ${ }^{66,67}$ On the contrary to our results, Baldassarri et al ${ }^{68}$ reported that the additive technique of the $3 \mathrm{D}$ printed wax pattern showed a notable limitation through polymerization shrinkage when compared to the subtractive milled techniques in the construction of hybrid implant abutments. It is important also to mention that the accuracy of the dental restorations fabricated by $3 \mathrm{D}$ printing depends upon the thickness of the print layer. $12 \mu \mathrm{m}$ layer thickness was used in this study to guarantee the accuracy of the abutment although this parameter could affect the speed of the printing negatively. ${ }^{69,70}$ The mode of failure of this group (E.max CAD) showed also type 3 (Fig. 10) revealing the strong bond between lithium disilicate material and the cement as group II (E.max Press) owing to the similarity of the chemical composition of both materials.

Bonding to zirconia ceramics has always been a challenge for prosthodontists. Numerous physicochemical surface treatments and different cement types have always been attempted to acquire a successful long-term durable bond between zirconia and resin cements. ${ }^{71-74}$ Regarding zirconia all-ceramic abutments, the retentive values of $\mathrm{Zr}$ CAD group (group I) showed statistically significant lower values than E.max CAD group (group III), but no statistically significant difference between $\mathrm{Zr}$ CAD group (group I) and PEEK CAD group (group IV) was found. Therefore, the second null hypothesis was partially accepted. This finding may be due to the quasi-chemical inertness of non-etchable zirconia material owing to its highly crystalline content and the lack of glass phase. ${ }^{40}$, 47, 75 However, the recommended surface treatment for zirconia ceramics has been implemented in this study. The fitting surface of zirconia abutments was sandblasted using $50 \mu \mathrm{m}$ alumina particles to improve the micromechanical bonding which increased the surface roughness and thus increasing the surface area available for bonding followed by application of zirconia primer (MKZ-primer) as recommended by manufacturer's instructions to ensure chemical bonding. Furthermore, resin cement used in this study contains MDP functional acidic monomer in its composition which proved its efficacy for bonding to zirconia ceramics. ${ }^{72}$

Additional challenge has been faced within this combination; zirconia ceramic over titanium base, which is bonding to titanium itself. Both zirconia and titanium are two complicated interfaces for bonding due to increased opacity, inadequate photopolymerization and incompetent common surface treatment. ${ }^{76-80}$ The surface of the Ti-base was treated with metal primer (MKZ primer) to ensure adequate bonding between titanium base and adhesive resin cement. Following manufacturer instructions, no mechanical surface treatment is needed with this type of Ti-Base owing to the laser micro-texturing feature supplied by the manufacturer as micro-mechanical mean to enhance roughness and wettability of the surface. ${ }^{81}$

Bergamo et al ${ }^{41}$ reached comparable results for pull-out testing of zirconia crowns over TiBase abutments. They mentioned the importance of sandblasting of the Ti-Base to maximize the retention of adhesive resin cement. Zahoui et al ${ }^{40}$ also examined the retention of zirconia crowns 
on Ti-Base with different Ti-Base height, cement type and surface treatment. They declared the significance of Ti-Base sandblasting in conjunction with zirconia tribochemical silica coating to increase the retention values. Conversely, another study revealed higher macroshear bond strength values of zirconia than lithium disilicate when cemented on Ti-Base. However, their study was conducted on flat specimens without including the clinically relevant factors as taper and height of the Ti-Base itself. ${ }^{82}$

Regarding the mode of failure of the samples of ZrCAD group (group I), type 1 was the predominant failure type (Fig. 8). This finding confirmed the complexities and difficulties related to zirconia bonding. Nouh et al ${ }^{17}$ noted $15.6 \%$ adhesive failures related to zirconia hybrid abutments during chewing simulation. Protopapadaki et al ${ }^{83}$ and Kim et al ${ }^{84}$ found also the same adhesive failures of zirconia abutments after static compressive testing upon analyzing the mode of failure of the samples in their studies.

The successful secure bonding to PEEK is considered as an essential requirement for this material to prove its efficacy to be used as definitive implant abutment solution. Regarding the PEEK abutment, the results revealed that there was a statistically significant difference between retention values of E.max CAD (group II) and PEEK CAD (group IV) with the latter having lower values. This may be attributed to the chemical inertness, low surface energy and surface modification resistance of the PEEK material. The high hardness and strength values of the PEEK hinders its surface roughening techniques. ${ }^{85}$ Though, comparable values were detected between $\mathrm{Zr}$ CAD and PEEK CAD groups with insignificant difference found between them confirming the fact that both materials are complicated in bonding. In the current study, the fitting surface of PEEK abutments were treated with $50 \mu \mathrm{m} \mathrm{Al}_{2} \mathrm{O}_{3}$ particles followed by application of Visio.Link adhesive following manufacturer instructions. These surface treatments may have resulted in similar results as zirconia abutments although these are far below that of etchable lithium disilicate abutments. Sandblasting of PEEK removes the contaminants from the surface and increases surface irregularities resulting in increase in the bonding contact area as described in previous study. ${ }^{86}$ Even though the high strength and hardness of the PEEK material hinders the methods used for surface roughening, several studies concluded that sandblasting of PEEK enhances the micromechanical bonding with resin cement and reflected through both high bond strength values and SEM revealing irregular pattern with large grooves and flow of the adhesive resin cement within these grooves. ${ }^{42,87-89}$

Not only the surface topography has been discussed before, but also the significance of the chemical surface conditioning has been reviewed for PEEK restorations. ${ }^{90}$ It was assumed that surface irregularities alone are not sufficient to secure a durable bond between PEEK and resin cement. ${ }^{91}$ In the current study, Visio.Link adhesive was applied following sandblasting. Visio.Link adhesive (MMA-containing adhesive) application has been reported to improve of chemical bonding to PEEK. ${ }^{92-94}$ It has been assumed that adhesives containing methylmethacrylate (MMA) and pentaerythritolacrylate (PEITA) along with extra dimethacrylate increased bond strength significantly, as MMA triggered the PEEK surface to swell while dimethacrylate monomers allowed the connection to composite resin through two binding sites represented as carboxyl groups. ${ }^{42,43,87,95}$ Many previous studies revealed high bond strength values after the use of Visio.Link on various pretreated PEEK surface. ${ }^{91,96,97}$

Moreover, the DTK adhesive resin cement was selected in this study due to its ability to enhance chemical bond between adhesive and PEEK as it is MDP-based dual cure adhesive resin cement. ${ }^{95}$ 
The failure mode revealed for PEEK CAD was type 2 which suggests the adequate bond between the treated PEEK surface the cement used (Fig. 9). Thus, it was speculated that the retention values between PEEK material and cement exceeds the cohesive strength of the cement itself.

The pull-out retention values of the PEEK Press showed the lowest values with significant difference between it and other materials and techniques used in this study. This may be attributed to the technique itself, being more operator-dependent as all the parameters including preheating process and vacuum pressing method may have influenced the final product negatively. In agreement with this finding, it has been stated previously that PEEK produced by CAD/CAM technology created more quality-controlled PEEK restorations than pressing technique owing to the improved pre-pressing industry of the CAD/CAM blanks which enhances the overall mechanical properties of the restoration and reduced risks of porosities within the material itself. ${ }^{95} \mathrm{On}$ the other hand, the application of sandblasting in conjunction with Visio.Link and adhesive resin cement might have resulted in better bonding efficacy of CAD/CAM PEEK group than direct pressing technique of the material on TiBase without any mechanical or chemical treatment to the material itself. The material manufacturer claims that the PEEK can be pressed over Ti-base, however they recommend the use of Ti-base of the same company which involves multiple horizontal grooves opposed to the relatively smooth Ti-base used in this study. In our opinion, the pressing technique might have needed the use of Ti-Base with macroretentive features to produce higher bond strength values. The failure mode of PEEK Press group (group V) showed minimal PEEK material being attached to the Ti-bases in some parts but almost only $10 \%$ of the bonding area and the other bonding parts were almost clear from any PEEK material (Fig. 11). Thus, the bonding approach between PEEK Press and Ti-bases need more investigations and improvements.
The type of the cement is also an important factor affecting the durability of the bond between abutment and Ti-base. Higher retention values were found upon cementation of implant-supported restorations on Ti-base using adhesive resin cement irrespective of the restoration material type. ${ }^{8} \mathrm{MDP}$ containing adhesive resin cement was used in this study owing to its proven efficient bonding with TiBase, zirconia copings and PEEK. ${ }^{95,98}$ Dhesi et al ${ }^{82}$ stated that both the ceramic and cement type have impact on bond strength values upon bonding on Ti-Base, presenting high mean bond strength values of zirconia abutments on Ti-Base with MDPcontaining adhesive resin cement than lithium disilicate bonded to Ti-Base using the same cement type. This was on the contrary to our results.

In the present study, pull-out retention test was the chosen method of testing. Although the commonly used methods to assess the bonding durability are shear, tensile, microtensile or push-out tests owing to the more controlled laboratory parameters and reproducibility of results, the authors preferred to be more clinically-relevant through reproducing all the clinical parameters as the Ti-Base height, geometry, surface pretreatments of both the Ti-Base and the materials on the top as well as the luting cements that might affect the retention values of the whole assembly. ${ }^{40,72}$ This was in agreement with several studies which evaluated the retentive strength of implant-supported restorations previously through pull-out tests. ${ }^{40,41,46,80}$

Thermocycling aging was applied to all samples of all groups before pull-out retention testing due to the importance of imitating the intra-oral thermal fluctuations that occurred normally due to drinking, eating, and breathing. The significance of thermocycling aging during laboratory studies of bonding durability has always been highlighted in several studies. ${ }^{43,87-89}$ However, mechanical chewing simulation was not applied, which could be considered as a limitation in this study. Another limitation with- 
in this study is the testing without the crown over the implant abutments which is not representing the actual clinical situation, nevertheless the main aim of the study was the retention between different abutment materials and techniques and the Ti-base, hence it was preferred not to include an extra variable which could complicate the results.

Finally, there is no minimal acceptable value for pull-out test that might guarantee the long-term retentiveness of the implant-supported prosthesis previously agreed upon in the literature. However, the results of this study might be used as preliminary guidelines regarding the behavior of different materials and techniques used as implant abutments over Ti-base.

Different strategies have been always suggested regarding titanium bonding, surface treatment of zirconia, lithium disilicate and hybrid materials. The combination possibilities of the available ceramic and hybrid materials in addition to different types of cements and fabrication techniques open the dental implant field for several treatment protocols. Further investigations are required to examine these implant abutment materials used on different heights, shapes, and different surface pretreatments of Ti-Base.

\section{CONCLUSIONS}

Within the limitations of this study, the following conclusions can be drawn:

1. Lithium disilicate ceramics showed the best results including both CAD/CAM and pressable techniques.

2. $\mathrm{CAD} / \mathrm{CAM}$ zirconia ceramics and $\mathrm{CAD} / \mathrm{CAM}$ PEEK abutments have comparable retention values to Ti-Bases.

3. Pressing PEEK on Ti-Base without macroretentive features is not a reliable alternative to other ceramics used in this study.
4. More clinical trials are still needed to confirm the success of different abutment materials and techniques used to construct mesostructures on Ti-Base.

\section{REFERENCES}

1. Jung RE, Zembic A, Pjetursson BE, Zwahlen M, Thoma DS. Systematic review of the survival rate and the incidence of biological, technical, and esthetic compilcations of single crowns on implans reported in longitudinal studies with a mean follow-up of 5 years. Clin Oral Implant Res 2012;23(6):2-21.

2. Maló P, De Arauja Nobre M, Lopes A, Ferro A, Gravito I. Single tooth rehabilitation supported by dental implants used in an immediate provisionalization protocol: report on long term outcome with retrospective follow-up. Clin Implant Dent Relat Res 2015;17(suppl):e511-9.

3. Buser D, Janner SF, Wittenben JG, Brägger U, Ramseier CA, Salvi GE. 10-year survival and success rates of 511 titanium implants with a sandblasted and acid-etched surface: a retrospective study in 303 partially edentulous patients. Clin Implant Dent Relat Res 2012;14:839-851.

4. Saadoun AP, Le Gall MG, Touati B. Current trends in implantology: Part II- treatment planning, aesthetic considerations, and tissue regeneration. Pract Proced Aesthet Dent 2004;16:707-714.

5. Tischler M. Dental implants in the esthetic zone. Considerations for form and function. NY Dent $\mathrm{J}$ 2004;70:22-6.

6. Byrne D, Houston F, Cleary R et al. The fit of cast and premachined implant abutments. J Prosthet Dent 1998;80:184-192.

7. Sae-Lee D, Chanatepapom P, Puasiri S, Suwannarong W, Raunglertpanyakul C. The precision between implant fixture and titanium base abutment connection and cement gap between titanium base abutment and zirconia crown. KDJ 2018;21(2):83-93.

8. Lopes A, Machado C, Bonjardim L, Bergamo E, Ramalho I, Witek L, Coelho P, Bonfante E. The effect of CAD/CAM crown material and cement type on retention to implant abutments. J Prosthodont 2019;28:e552-e556.

9. Martinez-Rus F, Ferreiroa A, Özcan M, Bartolomé JF, Pradies G. Fracture resistance of crowns cemented on titanium and zirconia implant abutments: a comparison of 
monolithic versus manually veneered all-ceramic systems. Int J Oral Maxillofac Implants 2012;27:1448-1455.

10. Watkin A, Kerstein RB. Improving darkened anterior peri-implant tissue color with zirconia custom implant abutments. Compend Contin Educ Dent 2008;29:238-240, 242.

11. Vagkopoulou T, Koutayas O, Koidis P, Strub J. Zirconia in dentistry: Part 1. Discovering the nature of an upcoming bioceramic . Europ J Esthet Dent. 2009;4:130-151.

12. Foong JK, Judge RB, Palamara JE, Swain MV. Fracture resistance of titanium and zirconia abutments: an in vitro study. J Prosthet Dent 2013;109(5):304-312.

13. Alqahtani F, Flinton R. Post-fatigue fracture resistance of modified prefabricated zirconia implant abutments. J Prosthet Dent 2014;112:299-305.

14. Stimmelmayr M, Edelhoff D, Güth JF, Erdelt K, Happe A, Beuer F. Wear at the titanium-titanium and the titaniumzirconia implant abutment interface: A comparative in vitro study. Dent Mater 2012;28:1215-1220.

15. Passos S, Linke B, Larjava H, French D. Performance of zirconia abutments for implant-supported single-tooth crowns in esthetic areas: A retrospective study up to 12 year follow-up. Clin Oral Impl Res 2016;27:47-54.

16. Zembic A, Philipp A, Hämmerle C, Wohlwend A, Sailer I. Eleven-year follow-up of a prospective study of zirconia implant abutments supporting single all-ceramic crowns in anterior and premolar regions. Clin Implant Dent Relat Res 2015;17:e417-e426.

17. Nouh I. Kern M, Sabet A, Aboelfadl A, Hamdy A, Chaar M. Mechanical behavior of all-ceramic hybrid-abutmentcrowns versus hybrid-abutments with separate crowns- A laboratory study. Clin Implant Oral Res 2019;30:90-98.

18. Zarauz C, Pitta J, Pradies J, Sailer I. Clinical recommendations for implant abutment selection for single implant reconstructions: customized vs. standardized ceramic and metallic solutions. Int $\mathrm{J}$ Periodontics Restorative Dent 2020;40:31-7.

19. Linkevicius T, Vaitelis J. The effect of zirconia or titanium as abutment material on soft peri-imlant tissues: a systematic review and meta-analysis. Clin Oral Implants Res 2015;26(suppl):s139-147.

20. Pitta J, Zaraus C, Pjetursson BE, Sailer I, Liu X, Pradies G. A systematic review and meta-analysis of the influence of abutment material on peri-implant soft tissue color measured by spectrophotometry. Int $\mathrm{J}$ Prosthodont 2020;33:39-47.

21. Staubli N, Walter C, Schmidt JC, et al. Excess cement and the risk of peri-implant disease- a systematic review. Clin Oral Implants Res 2017;28:1278-1290.

22. Wilson TG Jr. the positive relationship between excess cement and peri-implant disease: a prospective clinical endoscopic study. J Periodontol 2009;80:1388-1392.

23. Korsch M, Obst U, Walther W. Cement-associated periimplantitis: a retrospective clinical observational study of fixed implant-supported restorations using a methacrylate cement. Clin Oral Implants Res 2014;25:797-802.

24. Taha D, Nour M, Zohdy M, El-Etreby A, Hamdy A, Salah T. The effect of different wax pattern fabrication techniques on the marginal fit of customized lithium disilicate implant abutments. J Prosthodont 2019;28:1018-1023.

25. Panadero R, Fons-Font A, Rodriguez J, Ruiz M, Highsmith J, Ruiz MF. Zirconia versus metal: a preliminary comparative analysis of ceramic veneer behavior. Int $\mathrm{J}$ Prosthodont 2012;25:294-300.

26. Rosentritt M, Rembs A, Behr M, Hahnel S, Preis V. In vitro performance of implant-supported monolithic zirconia crowns: influence of patient specific toothcolored abutments with titanium adhesive bases. J Dent 2015;43:839-845.

27. Tinschert J, Natt G, Hassenpflug S, Spiekermann H. Status of current CAD/CAM technology in dental medicine. Int J Comput Dent 2004;7:25-45.

28. Guilherme NM, Chung KH, Flinn B, Zheng C, Ragriodski A. Assessment of reliability of CAD/CAM tooth-colored Implant custom abutments. J Prosthet Dent 2016; 116:206213.

29. Honda J, Komine F Kamio S, Taguchi K, Blatz M, Matsumuru H. Fracture resistance of implant-supported screw retained zirconia-based molar restorations. Clin Oral Implants Res 2017;28:1119-1126.

30. Li D, Guo J, Wang X, Zhang S, He L. Effects of crystal size on the mechanical properties of a lithium disilicate glass ceramic. Material Science and Engineering 2016;669:332339.

31. Harada K, Ragriodski A, Chung K, Flinn B, Dogan S, Manci L. A comparative evaluation of the translucency of zirconia and lithium disilicate for monolithic restorations. J Prosthet Dent 2016;116:257-263. 
32. Güngor M, Nemli S, Yilmaz H, Aydin C. Fracture resistance of different implant supported ceramic abutment/ crown systems. Eur Oral Res 2019;53(2):80-87.

33. Silva N, Teixeira H, Silveira L, Bonfante E, Coelho P, Thompson V. Reliability and falure modes of a hybrid ceramic abutment prototype. J Prosthodont 2018;27:83-87

34. Obermeier M, Ristow O, Erdelt K, Beuer F. Mechanical performance of cement- and screw-retained all-ceramic single crowns on dental implants. Clin Oral Investig 2018;22:981-991.

35. Conejo J, Kobayashi T, Anadioti E, Blatz M. Performance of CAD/CAM monolithic ceramic implant-supported restorations bonded to titanium inserts: a systematic review. Eur J Oral Implantol 2017;10(suppl):139-146

36. Ebert A, Hedderich J, Kern M. Retention of zirconia ceramic copings bonded tot titanium abutments. Int $\mathrm{J}$ Oral Maxillofac Implants 2007;22(6):921-927.

37. Schiessl C, Schaefer L, Winter C et al. Factors determining the retentiveness of luting agents used with metal- and ceramic-based implant components. Clin Oral Investig 2013;17:1179-1190.

38. Covey D, Kent D, St Germain H, et al. Effects of abutment size and luting cemet type on the uniaxial retention force of implant-supported crowns. J Prosthet Dent 2000;83:344-348.

39. Kent D, Koka S, Froeschle M. Retention of cemented implant-supported restorations. J Prosthodont 1997;6: 193-196.

40. Zahoui A, Bergamo E, Marun M, Silva K. Cementation protocol for bonding zirconia crowns to titanium base CAD/CAM abutments. Int J Prosthodont 2020;33: 527-535.

41. Bergamo E, Zahoui A, Ikejiri L, Marun M, Silva K, Coelho P, Soares S, Bonfante E. Retention of zirconia crowns to Ti-base abutments: effect of luting protocol, abutment treatment and autoclave sterilization.J Prosthodont Res $2021 ; 65: 1-5$.

42. Caglar I, Ates S, Duymus Y. An in-vitro evaluation of the effect of various adhesives and surface treatments on bond strength of resin cement to polyetheretherketone. J Prosthodont 2019;28 (1):e342-e349.

43. Stawarczyk, B, Keul C, Beuer F, Roos M, Schmidlin PR. Tensile bond strength of veneering resins to PEEK: impact of different adhesives. Dent Mater 2013;32(3):441-448.
44. Pitta J, Burkhardt F, Mekki M, Fehmer V, Mojon P, Sailer I. Effect of airborne-particle abrasion of a titanium base abutment on the stability of the bonded interface and retention forces of crowns after artificial aging. J Prosthet Dent 2020; Article in press available online.

45. Edelhoff D, Schweiger J, Prandtner O, Stimmlemayr M, Guth JF. Metal-free implant-supported single-tooth restorations. Part I: Abutments and cemented crowns. Quintessence Int 2019;50:176-184.

46. Maltzahn N, Bernard S, Kohorst P. Two-part implant abutments with titanium and ceramic components: Surface modification affects etention forces-an in vitro study. Clin Oral Impl Res 2019;30:903-909.

47. Silva C, Soares S, Machado C, Bergamo E, Coelho P, Witek L, Ramalho I, Jalkh E, Bonfante E. Effect of CAD/ CAM abutment height and cement type on the retention of zirconia crowns. Implant Dent 2018;27:1-6.

48. Gehrke P, Alius J, Fischer C, et al. Retentive strength of two-piece CAD/CAM zirconia implant abutments. Clin Implant Dent Relat Res 2014;16:920-925.

49. Preis V, Hahnel Behr M, Bein L, Rosentritt M. In vitro fatigue fracture testing of CAD/CAM materials in implantsupported molar crowns. Clin Oral Investig 2017;33:427433.

50. Rosentritt M, Hahnel S, Engelhardt F, Behr M, Preis V. In vitro performance and fracture resistance of CAD/CAM fabricated implant-supported molar crowns. Clin Oral Investig 2017;21:1213-1219.

51. Ongun S, Kurtulmus-Yilmaz S, Meriç G, Ulusoy M. A coparative study on the mechanical properties of a polymer-infiltrated ceramic network material used for the fabrication of hybrid abutment. Materials 2018;11:1681. doi: 10.3390 .

52. Tan Pl, Gratton DG, Diaz-Arnold AM, et al. An in vitro comparison of vertical margin gaps of CAD/CAM titanium and conventional cast restorations. J Prosthodont 2008;17:378-383.

53. Schepke U, Meijer H, Kerdijk W, et al. Stock versus CAD/ CAM customized zirconia implant abutments-clinical and patient-based outcomes in a randomized controlled clinical trial. Clin Oral Implant Res 2017;19:74-84.

54. Beuer F, Schweiger J, Edelhoff D. Digital dentistry: an overview of recent developments for CAD/CAM generated restorations. Br Dent J 2008;204:505-511. 
55. Cocchetto R, Canullo L. The "hybrid abutment": a new design for implant cemented restorations in esthetic zones. Int J Esthet Dent 2015;10:186-208.

56. Reich S, Wichmann N, Nkenke E, et al. Clinical fit of all-ceramic three-unit fixed partial dentures, generated with three different CAD/CAM systems. Eur J Oral Sci 2005;113:174-179.

57. Guess PC, Vagkopoulou T, Zhang Y, et al. Marginal and internal fit of heat pressed versus CAD/CAM fabricated all-ceramic onlays after exposure to thermomechanical fatigue. J Dent 2014;42:199-209.

58. Ng J, Ruse D, Wyatt C. A comparison of the marginal fit of crowns fabricated with digital and conventional methods. J Prosthet Dent 2014;112:555-560.

59. Bae E, Jeong J, Kim W, Kim J. A comparative study of additive and subtractive manufacturing for dental restorations. J Prosthet Dent 2017;118:187-193.

60. Park J, Kim H, Kim J, Kim W. Comparison of prosthetic models produced by traditional and additive manufacturing methods. J Adv Prosthodont 2015;7:294-302.

61. Abdou J, Lyons K, Bennamoun M. Trends in computeraided manufacturing in prosthodontics: a review of the available streams. Int J Dent 2014;783948.

62. Weaver J, Johnson G, Bales D. Marginal adaptation of castable ceramic crowns. J Prosthet Dent 1991;66:747-753.

63. Vaezi M, Chianrabutra S, Mellor B, Yang s. Nultiple material additive manufacturing-Part 1: a review: this review paper covers a decade of research on multiple material additive manufacturing technologies which can produce complex geometry parts with different materials. Virtual Phys Prototyp 2013;18:19-50.

64. Bertsch A, Renaud P. Microstereolithiography. Stereolithiography : Materials, processes, and applications. New York: Springer 2011:81-112.

65. Ogden Km, Aslan C, Ordway N, et al. factors affecting dimensional accuracy of 3-D printed anatomical structures derived from CT data. J Digit Imaging 2015; 28:654-663.

66. Munoz S, Dickinson DP. Comparison of margin discrepancy of complete gold crowns fabricated using printed, milled, and conventional hand-waxed patterns. J Prosthet Dent 2017;118:89-94.

67. Shamseddine L, Mortada R, Rifai K, Chidiac JJ. Marginal and internal fit of pressed ceramic crowns made from con- ventional and computer-aided design and computer-aided manufacturing wax patterns: an in vitro comparison. J Prosthet Dent 2016;116:242-248.

68. Baldassarri M, Hjerppe J, Romeo D, et al. Marginal accuracy of three implant-ceramic abutment configurations. Int J Oral Maxillofac Implants 2012;27:537-543.

69. Barazanchi A, Li KC, Al-Amleh B, Lyons K, Waddell JN. Additive technology update on current materials and applications in dentistry. J Prosthodont 2017;26:156-163.

70. Favero CS, English J, Cozad B, Wirthlin J, Short M, Kasper F. Effect of print layer height and printer type on the accuracy of 3-dimensional printed orthodontic models. Am Orthodont Dentofacial Orthop 2017;152:557-565.

71. Inokoshi M, De Munck J, Minakuchi S, Van Meerbeek B. Meta-analysis of bonding effectiveness to zirconia ceramics. J Dent Res 2014;93:329-334.

72. Özkan M, Bernasconi M. Adhesion to zirconia used for dental restorations: A systematic review and meta-analysis. J Adhes Dent 2015;17:7-26.

73. Almehmadi N, Kutkut A, Al-Sabbagh M. What is the best available luting agent for implant prostheses? Dent Clin North Am 2019;63:531-545.

74. Khan AA, Al Kheraif AA, Jamaluddin S, Elsharawy M, Divakar DD. Recent trends in surface treatment methods for bonding composite cement to zirconia: a review. J Adhes Dent 2017;19:7-19.

75. Gracis S, Thompson VP, Ferencz JL, et al A new classification system for all-ceramic and ceramic-like restorative materials. Int J Prosthodont 2015;28:227-235.

76. Rabel K, Spies BC, Pieralli S, Vach K, Kohal RJ. The clinical performance of all-ceramic implant-supported single crowns: a systematic review and meta-analysis. Clin Oral Implants Res 2018;29(18):196-223.

77. Pjetursson BE, Valente NA, Strasding M, Zwahlen M, Liu $\mathrm{S}$, Sailer I. A systematic review of survival and complication rates of zirconia-ceramic and metal-ceramic single crowns. Clin Oral Implants Res 2018;29(16):199-214.

78. Larsson C, Wennerberg A. the clinical success of zirconia-based crowns: a systematic review. Int J Prosthodont 2014;27:33-43.

79. Sailer I, Muhlemann S, Kohal RJ, Spies B, Pjetursson BE, Lang NP et al. Reconstructive aspects: summary and consensus statements of group 3 . The $5^{\text {th }}$ EAO Consensus Conference 2018. Clin Oral Implants Res 2018;29(18)237-242. 
80. Almilhatti HJ, Neppelenbroek KH, Vergani CE, Machado A, Pavarina A, Giampaolo E. Adhesive bonding of resin composite to various titanium surfaces using different metal conditioners and a surface modification system. J Appl Oral Sci 2013;21:590-596.

81. Dess product catalogue 2020, Dess, Spain.

82. Dhesi G, Sidhu S, Husain N, Özcan M. Evaluation of adhesion protocol for titanium base abutments to different ceramic and hybrid materials, Eur J Prosthodont Rest Dent 2020;28:1-13.

83. Protopapadaki M, Monaco EA, Kim HI, Davis EL. Comparison of fracture resistance of pressable metal ceramic custom implant abutment with a commercially fabricated CAD/CAM zirconia implant abutment. J Prosthet Dent 2013;110: 389-396.

84. Kim J, Raigrodski A, Flinn B, Rubenstein J, Chung K. Implant abutments under static load. J Prosthet Dent 2013;109:255-263.

85. Zhou L, Qian Y, Zhu Y, Liu H, Gan K, Guo J. The effect of different surface treatments on the bond strength of PEEK composite materials. Dent Mater 2014;30:e209-e215.

86. Jin HY, Teng MH, Wang ZJ, Li X, Liang JY, Wang WX, Jiang S, Zhao BD. Comparative evaluation of BioHPP and titanium as a framework veneered with composite resin for implant-supported fixed dental prostheses. J Prosthet dent 2019; 122(4):383-388.

87. Keul C, Liebermann A, Schmidlin P, Roos M, Sener B, Stawarczyk B. Influence of PEEK surface modification on surface properties and bond strength to veneering resin composites. J Adhes Dent 2014;16(4):383-392.

88. El Tahwi R, Abdelhalim I, Amgad S. The effect of different surface treatments on retention strength of resin nano ceramic and PEEK esthetic restorations. Egyptian Dental Journal 2020;65(2): e1-e12.

89. Çulhaoğlu A, Özkir S, Şahin V, Yilmaz B, Kiliçarslan M. Effect of various treatment modalities on surface charac- teristics and shear bond strengths of polyetheretherketonebased core materials. J Prosthodont 2020;29(2):136-141.

90. Escobar M, Souza J, Barra G, Fredel M, Ozcan M, Henriques $\mathrm{B}$. On the synergistic effect of sulfonic functionalization and acidic adhesive conditioning to enhance the adhesion of PEEK to resin-matrix composites Dent Mater 2021;37 (4): 741-754.

91. Rosentritt M, Preis V, Behr M, et al. Shear bond strength between veneering composite and PEEK after different surface modifications. Clin Oral Investig 2015;19:739-744.

92. Heimer S, Schmidlin PR, Stawarczyk B. Discoloration of PMMA, composite and PEEK. Clin Oral Investig 2016;21:1191-200.

93. Uhrenbacher J, Schmidlin PR, Keul C, Eichberger M, Roos M, Gernet W, et al. The effect of surface modification on the retention strength of polyetheretherketone crowns adhesively bonded to dentin abutments. J Prosthet Dent 2014;112:1489-97.

94. Liebermann A, Wimmer T, Schmidlin PR, Schere H, Loffler P, Stawarczyk B, et al. Physicomechanical characterization of polyetheretherketone and current esthetic dental CAD/CAM polymers after aging in different storage media. J Prosthet Dent 2016;115:321-328.

95. Yousry M, Hussein S, Al Abbassy F. Evaluation of shear bond strength of high-performance polymers to its resin veneering and to dentin (in vitro study). Alexandria Dental Journal 2018;43:62-68.

96. Stawarczyk B, Taufall S, Roos M, et al. Bonding of composite resins to PEEK: the influence of adhesive systems and air abrasion parameters. Clin Oral Investig 2018;22:763-771.

97. Yavuz t Ozyilmaz OY, Dilber E, et al. Effect of different surface treatments on porcelain resin bond strength. J Prosthodont 2017;26:446-454.

98. Mehl C, Zhang Q, Lehmann F, Kern M. Retention of zirconia on titanium in two-piece abutments with self-adhesive resin cements. J Prosthet Dent 2018;120:214-219. 